\title{
Element Simulation of Welding Residual Stresses and Distortion in 5083 Incorporating Metallurgical Phase Transformation
}

\author{
Xiaohu Tian ${ }^{1, *}$, Juan Liao ${ }^{1}$, Peng Cheng ${ }^{2}$ and Yi Ling ${ }^{3}$ \\ ${ }^{1}$ College of Material Science \& Engineering, Chongqing University, Chongqing, China \\ ${ }^{2}$ State Grid Chengdu Electric Power Company, Chengdu, Sichuan Province, China \\ ${ }^{3}$ Chongqing Changan Automobile Co., Ltd, Chongqing, China \\ ${ }^{*}$ Corresponding author
}

\begin{abstract}
The objective of this study is to investigate the effects of metallurgical phase transformation on welding residual stress induced by MIG(metal inert-gas welding) butt-welding in 5083 . In the numerical simulations, two separate finite element models are studied. The first one describes a sequentially coupled thermal, mechanical model based on a FE(finite element) analysis software Abaqus, while the second one discusses a sequentially coupled thermal, metallurgical, mechanical model based on another software Sysweld. In the thermo-matallomechanical model, the dependency of yield stress upon temperature and phase fraction is taken into account. A comparative analysis of experimentally validated finite element models has been performed and the residual stress states with and without the metallurgical phase transformation are predicted. The results reveal that the inclusion of metallurgical phase transformation has an effect on the longitudinal residual stresses, but a negligible effect on the distortion.
\end{abstract}

Keywords-aluminum alloy; simulation; residual stress; distortion; phase transformation

\section{INTRODUCTION}

Aluminum alloy which has light weight, excellent formability, high corrosion resistance and recyclable is widely used in the automotive and shipbuilding industries [1]. Because of moderately high strength, excellent extrusion, and corrosion resistance, 5083 aluminum alloy is suitable for producing complex sectional material using in carriages structure [2]. However, the process of welding inevitably produces unwanted residual stresses in the welded parts. Particularly, tensile residual stresses near the weld area have adverse effects. Welding residual stress may promote brittle fracture, reduce the buckling strength and the fatigue life and increase stress corrosion cracking during service [3]. Thus, predicting the welding residual stresses accurately can help to assure the sound design and safety of the structure.

Recently, aluminum alloy welded structures have been the subject of various works produced. For instance, Cañas J et al. $[4,5]$ carried out a FE(finite element) analysis to calculate the tensile longitudinal residual stresses which existed over a distance of around 10-15 mm either side of the weld centerline and used blind hole drilling methods to assess the residual stress in MIG butt-welded plates of 5083-O aluminum alloy. Cheng C M [6] analyzed and compared the magnitude and differences of residual stresses in aluminum alloys at different single V-groove GTAW (gas tungsten arc welding) buttwelding angles in restrained or unrestrained conditions. Edwin Raja D J and Somasundaram K [7] proposed the development of finite element model which was called neural network model to predict the residual stresses in butt-welding. Zain-ulAbdein $\mathrm{M}$ et al. [8, 9] predicted the laser beam welding induced distortions and residual stresses with the commercial finite element software Abaqus. Other published works [10-14] focus upon factors affecting residual distortion in stiffened panels like loading and boundary conditions, geometry of the specimen, welding process parameters etc.

For aluminum alloy, to evaluate the residual stresses and distortion accurately, metallurgical phase transformation should be considered. Metallurgical analyses of 5083 have been studied by some researchers. Yang S L et al. [2] studied microstructures and properties of MIG joint of 5083 aluminum alloy used in the high-speed vehicle. Hirata $\mathrm{T}$ et al. [15] performed the relationship between the microstructure of stir zone and the mechanical property of FS-welded 5083 aluminum alloy. Robson J D et al. [16] established microstructural modeling for friction stir welding of aluminum alloys. Finite element analysis of metallurgical phase transformation in MIG(metal inert-gas welding) butt welding of 5083 is still rare to be found in the published work.

This work aims to predict welding residual stresses in the butt-welded 5083 aluminum alloy plates using two different strategies. A thermo-mechanical analysis without metallurgical phase transformation is performed using Abaqus; while a thermo-metallo-mechanical analysis with metallurgical phase transformation is done using Sysweld. Effects of metallurgical phase transformation on residual stresses in butt welding are further investigated.

\section{EXPERIMENTAL PROCEDURE}

5083 aluminum alloy was adopted in this experiment. The dimensions of the base plate used were $250 \mathrm{~mm} \times 90 \mathrm{~mm} \times 4$ 
$\mathrm{mm}$.The V-shape $\left(60^{\circ}\right)$ butt joint configuration, as shown in Figure I , was prepared for joining the plates. Filler wires of material Al-Mg alloy ER5356 and of diameter $1.6 \mathrm{~mm}$ were used to create weld bead.

Single-pass MIG butt weld was performed with a beam power of $2500 \mathrm{~W}$ and a travel speed of $7.5 \mathrm{~mm} / \mathrm{s}$. Weld pool was shielded using 99.99\% Argon gas with a flow rate of 15 L/min. The HDSG (Hole Drilling Strain-Gauge) method was used for measuring residual stresses. The application of this method and calculating residual stresses was discussed in details [17].

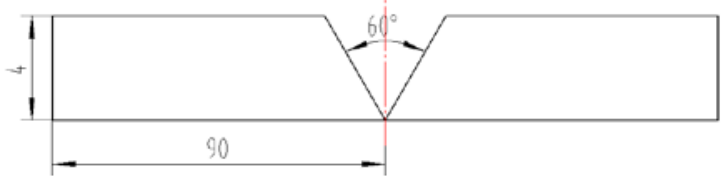

FIGURE I. GEOMETRY OF WELD CROSS SECTION

The stress measurements were made in seven points at the upper surface of the plates. Measuring the residual stress by the hole-drilling method is shown in Figure II . Figure II (a) is gluing position of strain gauge, and Figure II (b) is the strain measuring instrument. The relieved strains where was to mount three resistance strain gages were measured after drilling in the centre point of the gauges by a very high-speed drill. Because of the symmetry, only the stresses in one-half of the plate were measured.

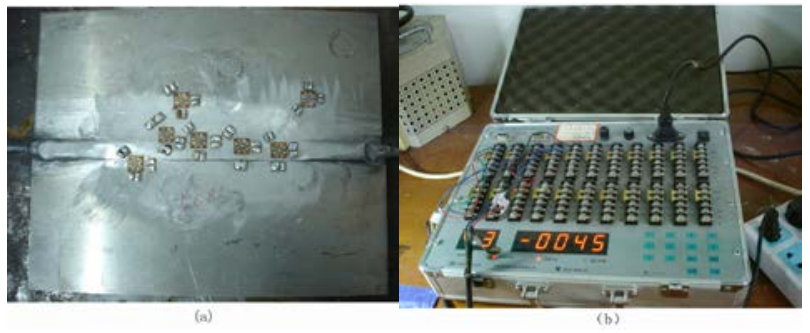

FIGURE II. HOLE DRILLING MEASURING SYSTEM, (A) GLUING POSITION OF STRAIN GAUGE, (B) STRAIN MEASURING INSTRUMENT

Although the angles between gages can be arbitrary, a 45degree angular increment leads to the simplest analytical expressions, and thus has become the standard for commercial residual stress rosettes. The principal stresses present at the hole can be obtained from the following equations (1), (2) after measuring released strain:

$$
\begin{gathered}
\sigma_{\text {max }}=\frac{\varepsilon_{1}+\varepsilon_{3}}{4 A}-\frac{1}{4 B} \sqrt{\left(\varepsilon_{3}-\varepsilon_{1}\right)^{2}+\left(\varepsilon_{3}+\varepsilon_{1}-2 \varepsilon_{2}\right)^{2}} \\
\sigma_{\text {min }}=\frac{\varepsilon_{1}+\varepsilon_{3}}{4 A}+\frac{1}{4 B} \sqrt{\left(\varepsilon_{3}-\varepsilon_{1}\right)^{2}+\left(\varepsilon_{3}+\varepsilon_{1}-2 \varepsilon_{2}\right)^{2}}
\end{gathered}
$$

where $\varepsilon_{1}, \varepsilon_{2}, \varepsilon_{3}$ are the released strains measured by the straingauges of a rosette at $\alpha_{1}, \alpha_{2}, \alpha_{3}$, respectively, $\alpha_{1}$ is the acute angle from the nearer principal axis to gage no. 1, while $\alpha_{2}=\alpha_{1}+45^{\circ}$ and $\alpha_{3}=\alpha_{1}+90^{\circ} ; \sigma_{\max }, \sigma_{\min }$ are the maximum (most tensile) and minimum (most compressive) principal stresses present at the hole location; $A$ and $B$ are the coefficients related to mechanical properties of the base metal and the hole diameter.

\section{Finite ElEMENT MODELING}

In this work, as the welded plate is symmetric with respect to the weld center line, a symmetric model is selected as the finite element (FE) analysis model. The FE model is shown in Figure III with eight-nodded brick elements. It has a fine grid in the welding zone, and the size of the mesh increases progressively away from the weld center line. The smallest element is $2 \mathrm{~mm} \times 0.5 \mathrm{~mm} \times 0.5 \mathrm{~mm}$. The length, the width and the thickness of the model are $250 \mathrm{~mm}, 90 \mathrm{~mm}$ and $4 \mathrm{~mm}$, respectively.

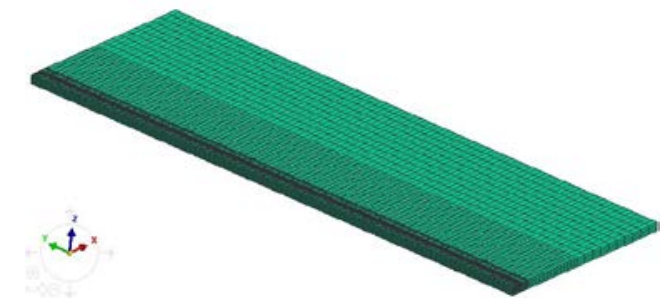

FIGURE III. PLATE MODEL USED FOR SIMULATION

As the plate is not clamped during welding, boundary conditions are just used to prevent rigid body motion. The boundary condition is shown in Figure IV. Because of the symmetry of the FE model, symmetry boundary condition is used in the symmetry plane. The point P1 in Figure IV is constrained in the $y$-direction and the $z$-direction; and the point P2 is constrained only in the z-direction. P1 and P2 are the start point and the end point of the line in the symmetry plane, respectively.

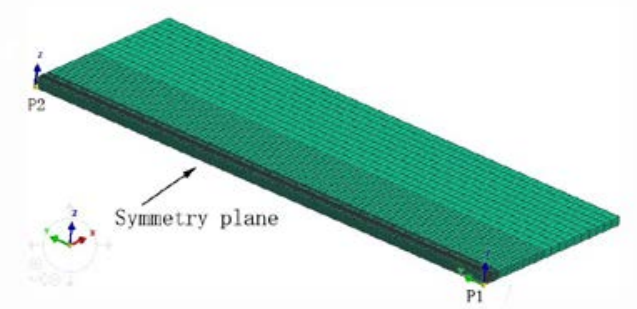

FIGURE IV. MECHANICAL BOUNDARY CONDITION

\section{HeAt SOURCE}

In this work, a double-ellipsoid heat source proposed by Goladk et al. [18] is used to represent the welding. Heat flux distribution is represented by the following equation:

For the front heat source 


$$
q_{\mathrm{v}}(x, y, z, t)=\frac{6 \sqrt{3} f_{f} Q}{b c_{h} a_{f} \pi \sqrt{\pi}} e^{-3\left[\frac{x^{2}}{b^{2}}+\frac{z^{2}}{c_{h}^{2}}+\frac{y^{2}}{a_{f}^{2}}\right]}
$$

For the rear heat source

$$
q_{\mathrm{v}}(x, y, z, t)=\frac{6 \sqrt{3} f_{r} Q}{b c_{h} a_{r} \pi \sqrt{\pi}} e^{-3\left[\frac{x^{2}}{b^{2}}+\frac{z^{2}}{c_{h}^{2}}+\frac{y^{2}}{a_{r}^{2}}\right]}
$$

where $Q$ is the magnitude of the heat input per unit time $(Q=\eta U I) ; f_{f}$ and $f_{r}$ are the parameters which give the fractions of the heat deposited in the front and the rear parts, respectively. Note that $f_{f}+f_{r}=2 . \eta$ is the arc efficiency which is assumed to be $70 \%$ for the MIG welding process. Therefore, two ellipsoidal sources are combined: one for the front half and the other for the rear half. The parameters $a_{r}, a_{f}, b$ and $c_{h}$ are related to the characteristics of the welding arc.

For Abaqus simulation, the heat source with a volumetric heat flux $q_{v}$ for the moving welding arc is modeled by a user subroutine in Abaqus. The parameters of the heat source are adjusted to create the desired melted zone. While for Sysweld, a double-ellipsoid heat source was calibrated using the in-built heat-source fitting tool and applies the heat flux as accurately as possible. Owing to the symmetry of butt joint, the heat source applied on one side of the stiffener essentially implies the presence of a similar heat source on the opposite side.

Although the filler wire of ER5356 is also Al-Mg Alloy, non obvious precipitation phase is observed in the weld metal [2]. For simulation, it is assumed that filler metal and base metal have the same thermal physical properties and mechanical properties.

\section{SimUlATION RESUlTS AND DisCUSSION}

\section{A. Thermo-metallurgical Analysis}

Dissolution of GP (Guinier-Preston) zones starts with an increase in temperature. In this work, as some new precipitates appear at certain higher temperatures only, the various precipitates present at different temperature ranges were identified.

The microstructure of 5083 base metal is $\alpha$-Al solid solution, with little amount of skeletal Al8Mg5 precipitate phase [2]. The precipitates present in the state of BM (base material) are called as Phase 1 . The recrystallized and weak material appearing in the HAZ(heat-affected zone) is called as Phase 2. The phase transformation from initial material (Phase 1) to weak material (Phase 2) defines the size of the heat affected zone. Phase 3 refers to the new material appearing in the FZ(fuse zones) after solidification and the material deposition in the form of filler wire [19].

In thermo-metallurgical analysis, Figure $\mathrm{V}$ is the contours of the fusion zones calculated by Abaqus and Sysweld. The cross-section contours at the butt joints represent the fusion zones for Abaqus and Sysweld. From this figure, the image of penetration shapes (molten zones) with peak temperature higher than $600{ }^{\circ} \mathrm{C}$ (the melting point of aluminum alloy) can be seen. In general, Abaqus and Sysweld have a good agreement. Minute difference for Abaqus and Sysweld appears negligibly small due to the various numerical effects in the finite element treatment of the heat source and the activation and deactivation management.

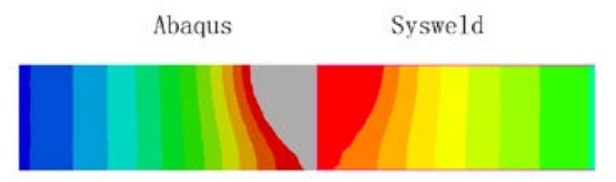

FIGURE V. SIMULATED FUSION ZONES; ABAQUS VS SYSWELD

The metallurgical phase fraction at different times during welding and cooling of the butt-joint assembly are simulated by Sysweld. The contours of residual metallurgical phase fractions in the fusion and heat-affected zones simulated by Sysweld are presented in Figure VI.

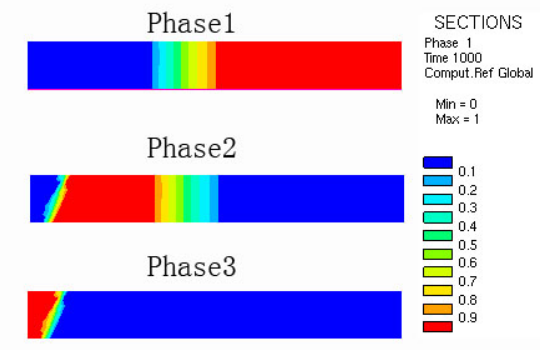

FIGURE VI. CONTOURS OF PHASE FRACTIONS CALCULATED BY SYSWELD

\section{B. Mechanical Analysis}

In the mechanical analysis, the same FE mesh used in the thermal analysis is employed. The thermo-physical properties are assumed identical with all the phases in both the Abaqus and Sysweld simulations. As far as temperature dependent mechanical properties are concerned, Abaqus simulation makes use of the properties of Phase 1 only, while Sysweld simulation exploits properties of all the three phases. The mechanical properties for different phases are reported in Table I .

\begin{tabular}{|c|c|c|c|c|c|}
\hline \multirow{2}{*}{ Phase } & \multicolumn{5}{|c|}{ Mechanical properties } \\
\hline & Temperature( ${ }^{\circ}$ & ${ }^{\circ} \mathrm{E}(\mathrm{Mpa})$ & $v$ & $\sigma(M P a)$ & $\rho\left(\mathrm{kg} \cdot \mathrm{m}^{-3}\right)$ \\
\hline \multirow{2}{*}{ Phase1 } & 20 & 70000 & 0.33 & 210 & 2750 \\
\hline & 600 & 1000 & 0.33 & 5 & 2590 \\
\hline \multirow{2}{*}{ Phase2 } & 20 & 70000 & 0.33 & 130 & 2750 \\
\hline & 600 & 1000 & 0.33 & 5 & 2590 \\
\hline
\end{tabular}

TABLE I. MECHANICAL PROPERTIES FOR DIFFERENT PHASES

The second step of the current analysis involves the use of the thermal histories predicted by the previous thermal model as an input (thermal loading) for a mechanical model. The 
material is assumed to follow an elastic-plastic law with isotropic hardening behavior (von Mises plastic model). Unlike the phase transformation in some steel from ferrite to austenite upon heating and then to martensite upon cooling, the transformation in 5083 is independent of the volumetric changes of the crystal lattice structure. In this study, phase transformation-induced volume change and plasticity are not taken into account. Ignoring this component, the total strain rate can be written as follows:

$$
\dot{\varepsilon}=\dot{\varepsilon}^{e}+\dot{\varepsilon}^{\text {th }}+\dot{\varepsilon}^{p}
$$

where $\dot{\varepsilon}$ is the total strain rate, $\dot{\varepsilon}^{e}$ is the elastic strain rate, $\dot{\varepsilon}^{\text {th }}$ is the thermal strain rate and $\dot{\varepsilon}^{p}$ is the plastic or inelastic strain rate.

The elastic part of the strain is defined by Young's modulus and Poisson's ratio, for isotropic material; while the thermal strain is defined with the help of a thermal dilatation coefficient. The transformation in 5083 is independent of the volumetric changes of the crystal lattice structure, therefore, the thermal dilatation coefficient for 5083 changes linearly with temperature.

The plasticity criterion specifies the 3D stress state with respect to the start of plastic flow and determines, therefore, the elastic domain is defined in space in terms of stress, temperature and hardening variables. The yield function, $f$ defines the limit to this elastic domain and may be written as follows:

$$
f\left(\sigma, T, H_{\text {iso }}\right)<0
$$

where $f$ is the yield function that defines the limit of the region of purely elastic response, $\sigma$ is the stress, $T$ is the temperature and Hiso shows the isotropic hardening parameters.

$$
\dot{\varepsilon}^{p}=\dot{\lambda} \frac{d g}{d \sigma}=\dot{\lambda} \frac{3}{2} \cdot \frac{S}{\sigma_{e f f}}
$$

where $\dot{\lambda}=\left(\frac{\langle f\rangle}{\eta}\right)^{n}$ and $\sigma_{\text {eff }}=\sqrt{\frac{3}{2} S: S}, \dot{\varepsilon}^{p}$ is the plastic strain rate, $g\left(\sigma, T, H_{\text {iso }}\right)$ is the flow potential, $\sigma_{\text {eff }}$ is the Von Mises effective stress, $S$ is the deviatoric stress, and $\eta$ and $n$ are the viscosity parameters [8].

The effect of metallurgical phase transformation takes the form of the yield strength, $\sigma_{y}=\sigma_{y}\left(\varepsilon_{\mathrm{p}}, T, p\right)$, where $p$ is the transformed fraction of each phase. As the metallurgical phase transformation, transformed fraction of each phase effects yield strength $\sigma_{\mathrm{y}}$. Thus, the dependency of yield stress on phase fraction and temperature is important to the numerical simulation result.

\section{Comparison of Welding Residual Stresses and Distortion}

Figure VII shows the longitudinal residual stresses (stresses in the welding direction) and the transverse residual stresses (stresses in the welding direction) predicted by Abaqus and Sysweld simulations in the weld region and HAZ. It is observed that there is a considerable difference between the cases with and without phase transformation (as shown in Figure VII(a)). Generally, without lower temperature phase transformation, the residual stress level in the FZ and HAZ is almost as large as the yield stress of the welded material at room temperature. For the case of thermo-mechanical analysis (Abaqus), it is found that the longitudinal stress approaches 210MPa and is largely tensile in the FZ and HAZ.

For the case of thermo-metallo-mechanical analysis (Sysweld), the longitudinal residual stresses in the FZ are still tensile, but its magnitude decreases obviously. The lower stresses can be explained by the phase transformation from initial material (Phase 1) to weak material (Phase 2). As the yield strength values of Phase 2 much lower than the Phase 1 (Table 1), increasing percentage of Phase 2 will result in a rather reduced level of stresses.

From the result shown in Figure VII(b), it can be observed that the transverse residual stresses are nearly wholly tensile and reduce to zero as the increasing distance from the weld center line. The transverse residual stresses resulting from Sysweld simulation follows a trend similar to that of Abaqus simulation. The results also reveal that the phase transformation has only a small influence on the transverse residual stresses. Here, the effect of phase transformation upon them can be neglected due to their already lower magnitudes.

Figure VIII shows the comparison of the contours of simulated out-of-plane displacements from Abaqus and Sysweld simulations. It is observed that the maximum displacement towards the free edges of the base plate reached around $0.35 \mathrm{~mm}$. Sysweld simulation shows an almost uniform out-of-plane displacement. Its magnitude is lessened by 0.03 $\mathrm{mm}$ compared to the values predicted through Abaqus simulation.
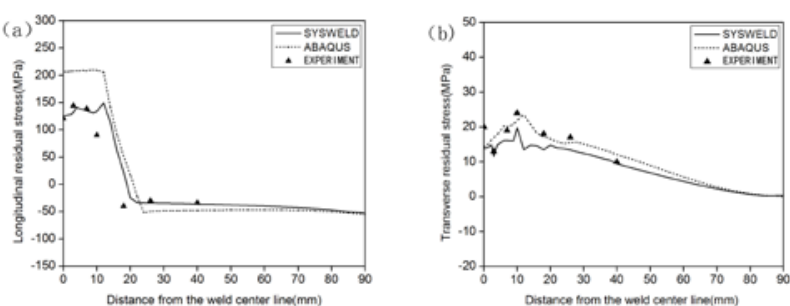

FIGURE VII. RESIDUAL STRESS DISTRIBUTION WITH AND WITHOUT PHASE TRANSFORMATION, (A) LONGITUDINAL RESIDUAL STRESS, (B) LONGITUDINAL RESIDUAL STRESS 


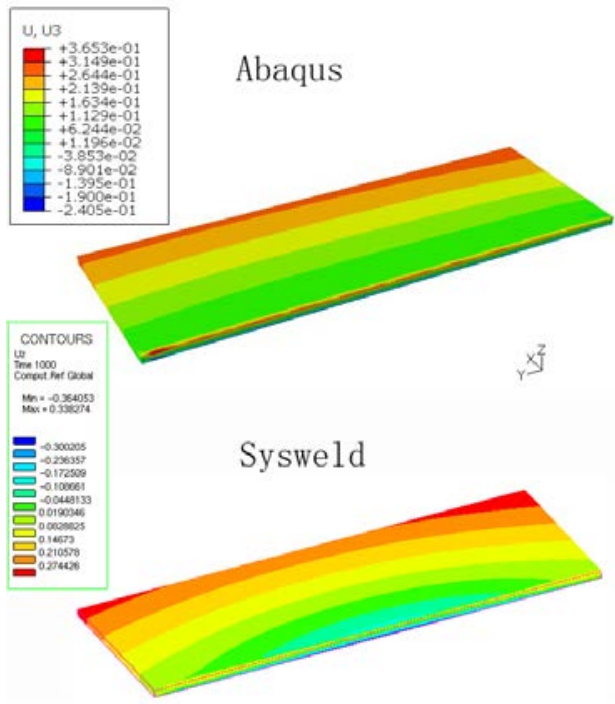

FIGURE VIII. COMPARISON OF RESIDUAL OUT-OF-PLANE DISPLACEMENT

\section{CONCLUSIONS}

A three-dimensional finite element model considering phase transformation is developed to analyze the MIG welding process and to simulate the residual stress and the welding distortion. The experimentally validated numerical models are developed using FE codes Abaqus and Sysweld.

(1) Based on the FE model, the effect of metallurgical phase transformation on the residual stresses and the welding distortion are investigated. The phase transformation leads to a decrease of the material properties which influence the residual stress states.

(2) The effects of metallurgical phase transformation on the longitudinal residual stresses are clearly shown in the large difference in peak value and the shape in FZ and HAZ.

(3) The metallurgical phase transformation has a very small effect on the transverse residual stresses and the distortion.

(4) According to the above simulation results, the metallurgical phase transformation of 5083 should necessarily be considered in order to predict the residual stress state accurately, especially longitudinal residual stresses, in the simulation of MIG welded structure.

\section{REFERENCES}

[1] HUANG K T, LIU T S, CHEN L H. Effect of microstructural feature on the tensile properties and vibration fracture resistance of friction stirred 5083 Alloy. Journal of Alloys and Compounds, 2011, 509 (27): 74667472.

[2] YANG S L, LUO B, LV R Y, MENG L C,LI Q L. Microstructures and Properties of MIG Joint of AA5083 Aluminum Alloy Used in HighSpeed Vehicle. Advanced Science Letters, 2011, 4 (3): 1098-1102 (5).

[3] TALJAT B, RADHAKRISHNAN B, ZACHARIA T. Numerical analysis of GTA welding process with emphasis on post-solidification phase transformation effects on the residual stresses. Materials Science and Engineering A, 1998, 246 (1-2): 45-54.
[4] CAÑAS J, PICÓN R, PARÍS F, MARÍN J C, BERMEJO A. Experimental and numerical analysis of residual stresses in welded $\mathrm{Al}$ 5083-O aluminum plates. Welding International, 1994, 8 (1): 30-35.

[5] CAÑAS J, PICÓN R, PARÍS F, BLAZQUEZ A, MARÍN J C. A simplified numerical analysis of residual stresses in aluminum welded plates. Computers and Structures, 1996, 58 (1): 59-69.

[6] CHENG C M. Butt-welding residual stress of heat treatable aluminum alloys. Journal of Materials Science and Technology, 2007, 23 (2): 217222.

[7] J EDWIN RAJA D, SOMASUNDARAM K. Modeling of residual stress in butt welding. Materials and Manufacturing Processes, 2011, 26 (7): 942-947 (6)

[8] ZAIN-UL-ABDEIN M, NELIAS D, JULLIEN J F, DELOISON D. Prediction of laser beam welding-induced distortions and residual stresses by numerical simulation for aeronautic application. Journal of Materials Processing Technology, 2009, 209 (6): 2907-2917.

[9] ZAIN-UL-ABDEIN M, NÉLIAS D, JULLIEN J F, DELOISON D. Experimental investigation and finite element simulation of laser beam welding induced residual stresses and distortions in thin sheets of AA 6056-T4. Materials Science and Engineering A, 2010, 527 (12): 30253039.

[10] CAMILLERI D, COMLEKCI T, GRAY T G F, THERM J. Thermal distortion of stiffened plates due to fillet welds e computational and experimental investigation. Journal of Thermal Stresses, 2006, 29 (2): 111-137.

[11] ZAIN-UL-ABDEIN M, NÉLIAS D, JULLIEN J F, DELOISON D. Thermo-mechanical Analysis of Laser Beam Welding of Thin Plate with Complex Boundary Conditions. International Journal Of Material Forming, 2008, 1 (Supplement 1): 1063-1066.

[12] MURPHY A, MCCUNE W, QUINN D, PRICE M. The characterisation of friction stir welding process effects on stiffened panel buckling performance. Thin-Walled Structures, 2007, 45(3): 339-351.

[13] SCHENK T, RICHARDSON I M, KRASKA M, OHNIMUS S. A study on the influence of clamping on welding distortion. Computational Materials Science, 2009, 45 (3), 999-1005.

[14] YAN D J,LIU X S, LI J, YANG J G, FANG H Y. Effect of strain hardening and strain softening on welding distortion and residual stress of A7N01-T4 aluminum alloy by simulation analysis. Journal of Central South University of Technology, 2010, 17 (4): 666-673.

[15] HIRATA T, OGURI T, HAGINO H, TANAKA T, CHUNG S W, TAKIGAWA Y, HIGASHI K. Influence of friction stir welding parameters on grain size and formability in 5083 aluminum alloy. Materials Science and Engineering A, 2007, 456 (1-2): 344-349.

[16] ROBSON J D, KAMP N, SULLIVAN A. Microstructural modeling for friction stir welding of aluminum alloys. Materials and Manufacturing Processes, 2007, 22 (4): 450-456.

[17] Vishay Micro-Measurements, Measurement of residual stresses by the hole drilling strain gauge method. Technical note TN-503, 2010: 19-33.

[18] GOLADK J, CHAKRAVARITI A, BIBBY M. A new finite element model for welding heat sources. Metallurgical and Materials Transactions B, 1984, 15 (2): 299-305.

[19] Gene Mathers. The welding of aluminum and its alloys. North America: CRC Press LLC, 2002. 